\title{
Suicide in doctors: a study of risk according to gender, seniority and specialty in medical practitioners in England and Wales, 1979-1995
}

\author{
K Hawton, A Clements, C Sakarovitch, S Simkin, J J Deeks
}

\begin{abstract}
Study objective-To investigate the suicide risk of doctors in England and Wales, according to gender, seniority and specialty.

Design-Retrospective cohort study. Suicide rates calculated by gender, age, specialty, seniority and time period. Standardised mortality ratios calculated for suicide (1991-1995), adjusted for age and sex.

Setting-England and Wales.

Subjects-Doctors in the National Health Service who died by suicide between 1979 and 1995 , identified by death certificates. Population at risk based on Department of Health manpower data.

Main results-Two hundred and twenty three medical practitioners in the $\mathrm{Na}$ tional Health Service who died by suicide or undetermined cause were identified. The annual suicide rates in male and female doctors were 19.2 and 18.8 per 100000 respectively. The suicide rate in female doctors was higher than in the general population (SMR 201.8; 95\% CI 99.7, 303.9), whereas the rate in male doctors was less than that of the general population (SMR 66.8; 95\% CI 46.6, 87.0). The difference between the mortality ratios of the female and male doctors was statistically significant $(p=0.01)$, although the absolute suicide risk was similar in the two genders. There were significant differences between specialties $(p=0.0001)$, with anaesthetists, community health doctors, general practitioners and psychiatrists having significantly increased rates compared with doctors in general hospital medicine. There were no differences with regard to seniority and time period.

Conclusions-There is an increased risk of suicide in female doctors, but male doctors seem to be at less risk than men in the general population. The excess risk of suicide in female doctors highlights the need to tackle stress and mental health problems in doctors more effectively. The risk requires particular monitoring in the light of the very large increase in the numbers of women entering medicine. (F Epidemiol Community Health 2001;55:296-300)
\end{abstract}

Doctors in several countries seem to have a relatively increased risk of suicide compared with the general population and to many other professional groups. ${ }^{1}$ In an international review of studies between 1958 and 1993, suicide rates were increased in doctors compared with general population rates in all the reports, although in a few studies the difference was not statistically significant. The risk seemed to be considerably more increased in female doctors than male doctors. ${ }^{1}$

There have been recent reports of an increased risk of suicide in doctors in England and Wales. ${ }^{2}{ }^{3}$ However, these were based on proportional mortality ratios, which, because they depend on comparison of numbers of deaths from a specific cause (that is, suicide) with those from all other causes, can be misleading, particularly if examined in a population with either high or low mortality from most causes, the latter being the case in doctors. ${ }^{4}$

Some studies have examined whether certain medical specialties are associated with especially high suicide rates, psychiatrists ${ }^{45}$ and anaesthetists ${ }^{67}$ receiving particular attention. Increasing concerns have recently been expressed about stress, mental health problems and suicidal ideas in doctors in the National Health Service, ${ }^{89}$ with thoughts of suicide being particularly frequently reported by general practitioners. ${ }^{9}$

We have investigated suicide rates in doctors in England and Wales for 1979 to 1995. In particular we have examined the age adjusted risk in doctors compared with the general population, focusing particularly on risk according to gender and age. Within doctors we have studied relative risk according to gender, seniority and specialty.

\section{Methods}

STUDY POPULATION

The Office for Population Censuses and Surveys (now Office for National Statistics) supplied us with death entries for all deaths in England and Wales between 1979 and 1995 of individuals resident in the United Kingdom whose occupations were recorded as medical practitioners (or equivalent) where an inquest verdict of suicide (ICD9 codes E950-E959) or undetermined cause ("open verdicts"; E980E989 excluding E988.8 $)^{10}$ had been registered. The open verdicts were included because of there being ample evidence that the majority of these are suicides. ${ }^{11}$ Throughout the rest of the paper suicide and open verdicts are combined and referred to as suicides. The death entries included information on gender, age, date of death, and method of suicide (including ICD9 E code). 
We searched medical directories for up to 10 years before the deaths for information about seniority and specialty where this was not available on the death certificate. For cases where any of this information was missing we then checked the General Medical Council Register. Each doctor was classified as a senior or junior grade (consultant or equivalent versus all other grades for hospital doctors, and partners versus trainees for general practitioners). For the cases where level of seniority was not known we made an assumption that doctors under 36 years of age were juniors and those aged 36 years or over were seniors. Doctors not employed within the NHS were excluded from the study.

NHS POPULATION STATISTICS FOR DOCTORS

The NHS Executive and the Government Statistical Service in Wales supplied us with annual population statistics for doctors in England and Wales for each year between 1979 and 1995. These data included the number of doctors in each specialty, and according to seniority, gender and age. For hospital doctors we included as seniors all those who were consultants or equivalent (for example, associate specialists (1987-95), medical assistants (1979-86), senior hospital medical officers with allowance (1979-86)). The remaining categories (that is, training grades) were grouped together as juniors. Doctors who worked both in general practice and hospital medicine (for example, clinical assistants) were counted as general practitioners.

\section{COMPARISON WITH SUICIDES IN THE GENERAL} POPULATION

For the purpose of comparing rates of suicide in doctors with general population rates, age and gender specific suicide rates for the population of England and Wales for the years 1979-1995 were calculated using data from the Twentieth Century Mortality Files ${ }^{12}$ for ICD9 codes E950-959; E980-989 excluding E988.8. These comparisons were conducted for men aged 25-64 years and women aged 25-59 years. The two different age bands were used because of the difference in traditional retirement ages for men and women.

\section{STATISTICAL ANALYSES}

To compare suicide rates in doctors with the general population, age adjusted standardised mortality ratios (SMRs) were calculated for male and female doctors separately. The mixture of 5 year and 10 year age bands used for the indirect standardisation (table 2) was determined by the format in which the NHS Executive reports numbers of doctors. The numbers of general practitioners by age and gender were only available for 1991 to 1995 . Therefore the analyses comparing rates in doctors with those in the general population were only conducted for this period. The SMRs are presented together with $95 \%$ confidence intervals. ${ }^{13}$ The significance of differences in mortality ratios between age bands was assessed by computing $\chi^{2}$ tests, and that between the SMRs of men and women was assessed by a $\mathrm{z}$ test.
Differences in suicide rates among doctors by age, gender, seniority and specialty were estimated using Poisson regression. Two datasets were analysed: the first contained data on gender and grade for all doctors, the second contained data on gender and specialty for senior doctors (consultants or partners in general practice). Separate terms were included in the models for sex, grade (junior/senior) and each specialty. In addition, terms for four time periods (1979-82, 1983-86, 1987-90, 199195) were included to investigate whether rates changed during the period of the study. Suicide rates are expressed as deaths per 100000 person years at risk together with $95 \%$ confidence intervals. Interaction terms were included in all models to investigate whether the differences between grades and specialties were the same in male and female doctors, and constant across time periods.

Statistical analyses were undertaken in STATA. ${ }^{14}$ Standardisation was performed in Excel.

\section{Results}

NUMBERS OF SUICIDES IN DOCTORS

We were notified of the deaths of a total of 329 doctors. Of these, 106 doctors were excluded; 86 had retired and 20 were not on the General Medical Council register. Suicide verdicts had been given for $87 \%$ of the remaining 223 doctors, and open verdicts for $13 \%$. There was no difference in gender distribution within the two categories of verdict (table 1). Level of seniority was identified for 167 of the 223 doctors. Twenty of the remaining 56 doctors were aged less than 36 years and classified as juniors while 36 were classified as seniors.

\section{COMPARISON WITH GENERAL POPULATION}

SUICIDE RATES

The age standardised SMR in male doctors indicates that their suicide risk was significantly lower than that of the general population whereas the SMR for suicide in female doctors indicates an increased suicide risk (table 2). In female doctors the suicide rate was twice that of women in the general population whereas the rate in male doctors was two thirds that of men in the general population. The difference between the mortality ratios of the female and male doctors was statistically significant $(z=2.5, p=0.01)$. No significant differences in mortality ratios were found between age groups in either men $\left(\chi^{2}=5.27, \mathrm{df}=5, \mathrm{p}=0.38\right)$ or women $\left(\chi^{2}=2.75, \mathrm{df}=4, \mathrm{p}=0.60\right)$. The numbers of suicides in each group were too small to

Table 1 Suicides and open verdicts (undetermined cause of death) in doctors in England and Wales who were registered with the General Medical Council, 1979-1995

\begin{tabular}{|c|c|c|c|}
\hline & \multicolumn{2}{|l|}{ Verdict } & \multirow[b]{2}{*}{$\begin{array}{l}\text { Total } \\
\text { Number } \\
(\%)\end{array}$} \\
\hline & $\begin{array}{l}\text { Suicide } \\
\text { Number } \\
(\%)\end{array}$ & $\begin{array}{l}\text { Open } \\
\text { Number } \\
(\%)\end{array}$ & \\
\hline Men & $147(75.4)$ & $21(75.0)$ & $168(75.3)$ \\
\hline Women & 48 (24.6) & $7(25.0)$ & $55(24.7)$ \\
\hline Total & 195 & 28 & 223 \\
\hline
\end{tabular}


Table 2 Comparison of suicide rates in doctors with total population suicide rates, by gender and age groups, 1991 to 1995

\begin{tabular}{|c|c|c|c|c|c|c|c|c|}
\hline \multirow[b]{2}{*}{$\begin{array}{l}\text { Age and sex } \\
\text { groups }\end{array}$} & \multicolumn{3}{|c|}{ Population in England and Wales 1991-1995 } & \multicolumn{3}{|c|}{ Doctors in England and Wales 1991-1995 } & \multirow[b]{2}{*}{$\begin{array}{l}\text { Expected doctors } \\
\text { suicides (based on } \\
\text { population rates) }\end{array}$} & \multirow[b]{2}{*}{$\begin{array}{l}\text { Standardised } \\
\text { mortality ratio }\end{array}$} \\
\hline & $\begin{array}{l}\text { Number } \\
\text { of suicides }\end{array}$ & $\begin{array}{l}\text { Person years } \\
\text { at risk }\end{array}$ & $\begin{array}{l}\text { Annual } \\
\text { suicide rate } \\
\text { (per 100000) }\end{array}$ & $\begin{array}{l}\text { Number } \\
\text { of suicides }\end{array}$ & $\begin{array}{l}\text { Person years } \\
\text { at risk }\end{array}$ & $\begin{array}{l}\text { Annual } \\
\text { suicide rate } \\
\text { (per 100000) }\end{array}$ & & \\
\hline \multicolumn{9}{|l|}{ Men } \\
\hline 25-29 & 2391 & 10699800 & 22.4 & 9 & 42022 & 21.42 & 9.4 & 95.8 \\
\hline $30-34$ & 2263 & 10163000 & 22.3 & 4 & 50693 & 7.89 & 11.3 & 35.4 \\
\hline $35-39$ & 1997 & 8768700 & 22.8 & 6 & 47400 & 12.66 & 10.8 & 55.6 \\
\hline $40-49$ & 3860 & 17369600 & 22.2 & 12 & 86298 & 13.91 & 19.2 & 62.6 \\
\hline $50-59$ & 2529 & 13504100 & 18.7 & 8 & 54474 & 14.69 & 10.2 & 78.4 \\
\hline $60-64$ & 939 & 6092700 & 15.4 & 3 & 13254 & 22.63 & 2.0 & 146.9 \\
\hline total & 13979 & 66597900 & 21.0 & 42 & 294141 & 14.28 & 21.0 & $66.8(46.6,87.0)$ \\
\hline \multicolumn{9}{|l|}{ Women } \\
\hline $25-29$ & 518 & 10284100 & 5.0 & 6 & 34593 & 17.34 & 1.7 & 344.3 \\
\hline $30-34$ & 551 & 9839800 & 5.6 & 2 & 25526 & 7.84 & 1.4 & 139.9 \\
\hline $35-39$ & 496 & 8667200 & 5.7 & 3 & 19959 & 15.03 & 1.1 & 262.7 \\
\hline $40-49$ & 1175 & 17319900 & 6.8 & 3 & 25907 & 11.58 & 1.8 & 170.7 \\
\hline $50-59$ & 993 & 13586100 & 7.3 & 1 & 12880 & 7.76 & 0.9 & 106.2 \\
\hline total & 3733 & 59697100 & 6.3 & 15 & 118865 & 12.62 & 7.4 & $201.8(99.7,303.9)$ \\
\hline
\end{tabular}

Table 3 Suicide rates by gender, time period and seniority, 1979-1995

\begin{tabular}{|c|c|c|c|c|}
\hline & $\begin{array}{l}\text { Annual suicide rates } \\
\text { per } 100 \text { 000 ( } 95 \% \\
\text { confidence intervals) }\end{array}$ & $\begin{array}{l}\text { Number } \\
\text { of suicides }\end{array}$ & $\begin{array}{l}\text { Person years } \\
\text { at risk }\end{array}$ & $\begin{array}{l}\text { Adjusted relative risks* } \\
\text { ( } 95 \% \text { confidence } \\
\text { intervals) }\end{array}$ \\
\hline \multicolumn{5}{|l|}{ Sex } \\
\hline Male & $19.2(16.4$ to 22.3$)$ & 168 & 876881 & Baseline \\
\hline Female & $18.8(14.2$ to 24.5$)$ & 55 & 292100 & $1.0(0.8$ to 1.4$)$ \\
\hline \multicolumn{5}{|l|}{ Time period } \\
\hline 1979-1982 & 23.7 (18.0 to 30.7$)$ & 58 & 244534 & Baseline \\
\hline 1983-1986 & $15.7(11.3$ to 21.3$)$ & 41 & 260875 & $0.7(0.4$ to 1.0$)$ \\
\hline 1987-1990 & $19.5(14.6$ to 25.4$)$ & 54 & 277506 & $0.8(0.6$ to 1.2$)$ \\
\hline 1991-1995 & $18.1(14.1$ to 22.9$)$ & 70 & 386066 & $0.8(0.5$ to 1.1$)$ \\
\hline \multicolumn{5}{|l|}{ Grades } \\
\hline Senior & 20.5 (17.4 to 24.0$)$ & 156 & 760644 & Baseline \\
\hline Junior & $16.4(12.7$ to 20.8$)$ & 67 & 408337 & $0.8(0.6$ to 1.1$)$ \\
\hline
\end{tabular}

^Adjusted for time period and sex.

Table 4 Numbers of suicides and relative risks by specialty among senior doctors, 1979-1995

\begin{tabular}{lccl}
\hline Specialty & $\begin{array}{l}\text { Number } \\
\text { of suicides }\end{array}$ & Years at risk & $\begin{array}{l}\text { Adjusted relative risks } \\
\text { (95\% confidence intervals) }\end{array}$ \\
\hline General medicine & 4 & 77916 & Baseline \\
General practice & 84 & 451664 & $3.6(1.3$ to 9.9$)$ \\
Anaesthetics & 13 & 38225 & $6.8(2.2$ to 20.8$)$ \\
Psychiatry & 9 & 37411 & $4.8(1.5$ to 15.5$)$ \\
Community health & 7 & 18872 & $8.0(2.3$ to 28.0$)$ \\
Surgery & 6 & 55951 & $2.1(0.6$ to 7.3$)$ \\
Radiology & 3 & 18757 & $3.2(0.7$ to 14.2$)$ \\
Obstetrics and gynaecology & 2 & 15071 & $2.6(0.5$ to 14.2$)$ \\
Public health & 2 & 8802 & $4.5(0.8$ to 24.4$)$ \\
Pathology & 1 & 28598 & $0.7(0.1$ to 6.1$)$ \\
Radiotherapy & 1 & 3895 & $5.0(0.6$ to 45.1$)$ \\
Accident and emergency & 0 & 5483 & 0 \\
\hline
\end{tabular}

^Adjusted for time period and sex.

reliably detect differences in the SMRs, but the youngest age group of both genders had relatively high ratios.

SUICIDE RATES BY YEAR, GENDER AND SENIORITY During the study period the estimated suicide rate among all doctors was 19.0 per 100000 person years at risk. There were no significant differences in suicide rates by gender $\left(\chi^{2}=0.02\right.$, $\mathrm{df}=1, \mathrm{p}=0.9)$, time period $\left(\chi^{2}=4.41, \mathrm{df}=3\right.$, $\mathrm{p}=0.2)$ or seniority $\left(\chi^{2}=2.37, \mathrm{df}=1, \mathrm{p}=0.12\right)$. Table 3 gives estimates of the relative suicide rates for each of these factors, adjusted for the other two. The results were similar when the doctors for whom seniority was imputed were excluded from the analyses.

SUICIDE RATES OF SENIOR DOCTORS BY SPECIALTY Specialties were known for 132 of the 156 senior doctors. We compared suicide rates in each of the specialties, taking general medicine as
KEY POINTS

- Suicide rates in doctors were significantly lower than in the general population in men but increased in women.

- Use of SMRs rather than PMRs to estimate risk probably explains the difference between the findings of this study and earlier ones.

- Suicide rates were increased (compared with general medicine) in anaesthetists, community health doctors, general practitioners and psychiatrists.

- Doctors' suicide rates require monitoring because of recent reports of increased stress and the greater number of women entering medicine

the baseline, adjusting for gender and time period (table 4 ). There were significant differences between the specialties $\left(\chi^{2}=34.48, \mathrm{df}=9\right.$, $\mathrm{p}=0.0001)$. Four specialties had suicide rates significantly higher than general medicine. In order of risk these were community health, anaesthetics, psychiatry and general practice. The pattern of suicide rates by gender and time period was similar in all specialties except community health, where the rate among the men was 12.3 times higher than among the women (test for interaction of gender and specialty $\left.\chi^{2}=18.88, \mathrm{df}=7, \mathrm{p}=0.009\right)$.

\section{Discussion}

Suicide rates in doctors in the NHS workforce are increased compared with the general population in female doctors but lower than the general population in male doctors. The absolute risk in this study was similar in male and female doctors. This is in marked contrast with the general population, in which rates are considerably higher in men than women. ${ }^{3}$ Several other studies from countries around the world have found a considerably increased risk of suicide in female doctors but also usually a smaller increased risk in male doctors. ${ }^{1}$ There was no evidence of a change in this pattern of risk over time. The increased risk in female doctors is of particular concern in the light of the steadily increasing number and proportion of women in the medical workforce. ${ }^{15}$ It is possible, however, that, as poor status integration 
has been used as an explanation for excess risk of suicide, ${ }^{16}$ as women in medicine become less and less of a minority their risk will decline.

The contrast between the findings of this study and those of other investigations from the UK in which increased risk was found in doctors of both genders ${ }^{23}$ is probably attributable to our having used mortality rates to calculate standardised mortality ratios. The previous investigations used proportional mortality ratios, which depend not only on the rate of suicide but also the rate of death from other causes in both the population under study and the comparison population. Where a population has a relatively low rate of death from other causes, as is the case for doctors, ${ }^{4}$ this can lead to inflated and misleading proportional mortality ratios.

Explanations for an excess risk of suicide in doctors found in previous investigations have focused partly on ease of access to dangerous means for suicide. ${ }^{1317}$ Similar arguments have been put forward for the apparent excess risk in certain other occupational groups of healthcare workers such as pharmacists, dentists, female nurses, and also other groups such as farmers and veterinary surgeons. ${ }^{23} 1819$ The greater tendency of women to commit suicide by self poisoning, a pattern that is even more pronounced in female doctors than in the general population, ${ }^{17}$ might be part of the explanation for the increased risk in female doctors (who would be very aware of what drugs are dangerous in overdose). However, male doctors also use self poisoning for suicide more often than men in genera ${ }^{17}$ so this is unlikely to be the sole explanation for the gender difference. The particular stresses facing female doctors would seem to be an equally if not more relevant explanation for this finding.

\section{SENIORITY AND AGE}

There seemed to be no difference in risk according to seniority. However, we had to use an assumption based on an age criterion to determine seniority where this was not known. There were also no marked differences in risk according to age group, although it is worth noting that there were relatively high SMRs for both genders in the youngest age group.

\section{SPECIALTIES}

The analysis of suicide risk by specialty is limited somewhat by there being relatively small numbers of deaths in most categories and by the fact that information on specialty could not be obtained in $18 \%$ of cases. Assuming that the missing cases are distributed across the specialties in proportion to the risk we have identified, we have confirmed the relatively higher risk found for anaesthetists in some previous studies, ${ }^{46}$ although not $a l l,{ }^{7}$ and for psychiatrists, ${ }^{5}$ although again findings have been inconsistent. ${ }^{20}$ We do not know whether our findings reflect particular occupational stresses in these groups, or choice of specialty being influenced by factors that might differentially influence risk. High levels of stress and dissatisfaction are reported for psychiatrists. ${ }^{21}$ In anaesthetists, easy access to dangerous means for suicide may be an important additional factor. ${ }^{17}$

The excess risk of suicide associated with general practice is in keeping with survey findings that more general practitioners than hospital consultants report suicidal thoughts ${ }^{9}$ and is of concern in the light of recent reports of stress and dissatisfaction among general practitioners. ${ }^{22}$ The excess risk in general practitioners could also be influenced by ready access to means.

The apparent excess risk in male doctors in community health is based on just seven deaths, but this risk may reflect the fact that men and women tend to have different reasons for choosing this as a specialty.

\section{METHODOLOGICAL LIMITATIONS}

We combined suicide verdicts with open verdicts, some of which would not have been suicides. This approach seems, however, to reflect more closely the true extent of suicide ${ }^{311}$ and we used a comparable method to obtain general population rates of suicide.

Another limitation is that in the collection of the data we had to rely on death certificate information and official registers, which in some cases may be misleading or incomplete. The extent of missing information about many of the doctors with regard to seniority and specialty (despite our going to considerable lengths to obtain it) was surprising and raises questions about how doctors' careers are tracked. The absence of manpower data combining age and gender in general practitioners for the period 1979-1990 meant that the comparison with general population rates and the gender and age comparisons were limited to the period 1991-1995.

In conclusion, the excess risk of suicide in female doctors in the NHS workforce is an important pattern that should be carefully monitored. This is especially so in the light of increasing numbers of women coming into medicine. Further work is required to determine factors that explain the apparent excess risk in certain specialties.

\section{Contributors}

Keith Hawton, Alison Clements, Sue Simkin, Jonathan J. Deeks and Charlotte Sakarovitch participated in the design and execution of the study, analysis of the data and writing of the paper. This study is part of a programme of research on suicide in high risk occupational groups conducted at the Centre for Suicide Research, University of Oxford Department of Psychiatry, with funding friversity of Oxford Department of Psychiatry, with funding from the Department of Health. Keith Hawton is lso supported by Oxford Mental Healthcare Trust and he and Sue Simkin are also supported by South East Region NHSE Research and Development Directorate. We thank Faith Barbour for assisting with identifying the specialties of the doctors, Aslög Malmberg for her input at the initiation of the project, Michael Goldacre and Trevor Lambert for their advice, the NHS Executive Statistics Workforce Department and the Government Statistical Service for Wales for providing data on doctors in the NHS, and the General Medical Council Registration Directorate and Royal College of General Practitioners Membership Office for their assistance.

Conflicts of interest: none.

1 Lindeman S, Laara E, Hakko $\mathrm{H}$, et al. A systematic review on gender-specific suicide mortality in medical doctors. $\mathrm{Br} \mathcal{F}$ Psychiatry 1996;168:274-9.

2 Charlton J, Kelly S, Dunnell K, et al. Suicide deaths in England and Wales: trends in factors associated with suicide deaths. Popul Trends 1993;71:34-42.

3 Kelly S, Bunting J. Trends in suicide in England and Wales, 1982-96. Popul Trends 1998;92:29-41. 
4 Carpenter LM, Swerdlow AJ, Fear NT. Mortality of doctors in different specialities: Findings from a cohort of 20,000 NHS hospital consultants. Occup Environ Med 1997;54:

5 Rich C, Pitts F. Suicide by psychiatrists: A study of medical specialists among 18,730 consecutive physician deaths during a 5-year period 1967-1972. F Clin Psychiatry 1980 41:261-3.

6 Lew EA. Mortality experience among anesthesiologists, 1954-1976. Anesthesiology 1979;51:195-9.

7 Neil HAW, Fairer JG, Coleman MP, et al. Mortality among male anaesthetists in the United Kingdom, 1957-83. BMf 1987;295:360-2.

8 Firth-Cozens J. The five years after qualification. The psychopathology of hospital life is keeping women doctors away. BMF 1994;309:1524-5.

9 Caplan RP. Stress, anxiety, and depression in hospital consultants, general practitioners, and senior health service managers. BMF 1994;309:1261-3.

10 World Health Organisation. Manual of the international statistical classification of diseases, injuries and causes of death. statistical classification of diseases, injuries and

11 Charlton J, Kelly S, Dunnell K, et al. Trends in suicide deaths in England and Wales. Popul Trends 1992;69:10-16. Office for National Statistics. The twentieth century mortality files (CD Rom). London: Office for National Statistics, 1997
13 Armitage P, Berry G. Statistical methods in medical research. 2nd ed. Oxford: Blackwell Scientific Publications, 1987.

14 StataCorp. Stata statistical software: release 6.0. College Station, TX: Stata Corporation, 1999

15 Lambert TW, Goldacre MJ. Doctors who qualified in the UK between 1974 and 1993: age, gender, nationality, marital status and family formation. Med Educ 1998;32: 533-7.

16 Gibbs J, Martin W. Status integration and suicide. Eugene: University of Oregon Press, 1964

17 Hawton K, Clements A, Simkin S, et al. Doctors who kill themselves: a study of the methods used for suicide. $Q \mathcal{F}$ Med 2000;93:351-7.

18 Kelly S, Charlton J, Jenkins R. Suicide deaths in England and Wales, 1982-92: the contribution of occupation and geography. Popul Trends 1995;80:16-25.

19 Hawton K, Simkin S, Malmberg A, et al. Suicide and stress in farmers. London: The Stationery Office, 1998.

20 Bergman J. The suicide rate among psychiatrists revisited. Suicide Life Threat Behav 1979;9:219-26.

21 Benbow SJ, Jolley DJ. Psychiatrists under stress. Psychiatric Bulletin 1998;22:1-2.

22 Firth-Cozens J. Individual and organizational predictors of depression in general practitioners. Br f Gen Pract 1998;48: 1647-51.

\section{1st Asia Pacific Forum on Quality Improvement in Health Care}

\section{Three day conference}

\section{Wednesday 19 to Friday 21 September 2001 \\ Sydney, Australia}

We are delighted to announce this forthcoming conference in Sydney. Authors are invited to submit papers (call for papers closes on Friday 6 April), and delegate enquiries are welcome.

The themes of the Forum are:

- Improving patient safety

- Leadership for improvement

- Consumers driving change

- Building capacity for change: measurement, education and human resources

- The context: incentives and barriers for change

- Improving health systems

- The evidence and scientific basis for quality improvement.

Presented to you by the BMJ Publishing Group (London, UK) and Institute for Healthcare Improvement (Boston, USA), with the support of the the Commonwealth Department of Health and Aged Care (Australia), Safety and Quality Council (Australia), NSW Health (Australia), and Ministry of Health (New Zealand).

For more information contact: quality@bma.org.uk or fax +44(0)20 73836869 